\title{
LOS HIJOS DE INMIGRANTES MEXICANOS EN ESTADOS UNIDOS DE NORTEAMÉRICA Y SUS ASPIRACIONES EDUCATIVAS: UNA NUEVA PROPUESTA TEÓRICA
}

\author{
Enrique Martínez Curiel \\ Universidad de Guadalajara \\ CU Valles \\ emarcuriel@aol.com
}

\section{RESUMEN}

El presente trabajo comparte una propuesta teórica para explorar el proceso de formación de las aspiraciones educativas de los hijos de inmigrantes mexicanos desde la óptica de la vida familiar, tomando en consideración distintos enfoques teóricos. El artículo parte de la aseveración de que «la familia es un punto estratégico para entender las dinámicas de los flujos de la inmigración (legal e ilegal) y del proceso de adaptación del inmigrante» (Rumbaut 1997: 4). La propuesta de análisis plantea abordar el objeto de estudio desde la dinámica interna de la vida familiar. Asimismo, es importante tomar en cuenta el contexto social y cultural del lugar de origen de las familias inmigrantes y el contexto de recepción.

Palabras clave: aspiraciones educativas, hijos de inmigrantes, vida familiar, enfoque teórico. 


\title{
THE CHILDREN OF MEXICAN IMMIGRANTS IN THE UNITED STATES AND THEIR EDUCATIONAL ASPIRATIONS: A NEW THEORICAL PROPOSAL
}

\begin{abstract}
This work is a theoretical proposal that uses a family life perspective to explore the construction of educational aspirations of Mexican immigrant children. It takes into consideration different theoretical approaches. The article begins by stating that «the family is a strategic element to understand the dynamics of both legal and illegal immigration flows and the immigrant's adaptation process» (Rumbaut, 1997: 4). The analytical proposal sets forth that the object of study must be approached at the level of the inner dynamics within family life. It is also important to take into account the social and cultural context of the place where family immigration originates, as well as the context of the receiving location.
\end{abstract}

Key words: educational aspirations, immigrant children, family life, theoretical approach. 


\section{INTRODUCCIÓN}

La formación de las aspiraciones educativas de los hijos de inmigrantes mexicanos en Estados Unidos sigue siendo un tema poco discutido y analizado por la investigación antropológica. ${ }^{1}$ La naturaleza interdisciplinaria del tema exige una revisión de las teorías que se han abordado desde distintas disciplinas. En este artículo se pondrán a discusión los dos enfoques teóricos que han intentado explicar las aspiraciones educativas de los hijos de inmigrantes: la perspectiva socioeconómica, mejor conocida como el modelo alcanzar el estatus; y la perspectiva sociocultural, conocida como el enfoque de las oportunidades bloqueadas. La propuesta teórica tiene como objetivo centrar el análisis en el impacto de la vida familiar en las aspiraciones educativas de los hijos de inmigrantes mexicanos, retomando la teoría de la asimilación segmentada, la cual permite comprender el proceso de adaptación de los hijos de inmigrantes en el sistema de estratificación social en la sociedad de acogida, proceso que ayudará a entender la formación de las aspiraciones educativas de los hijos de inmigrantes mexicanos.

El presente trabajo comparte una propuesta teórica con el propósito de explorar el proceso de formación de las aspiraciones educativas en los hijos de inmigrantes mexicanos desde la óptica de la vida familiar, tomando en consideración distintos enfoques teóricos. En ese sentido, partimos de la aseveración de que «la familia es un punto estratégico para entender las dinámicas de los flujos de la inmigración (legal e ilegal) y del proceso de adaptación del inmigrante» (Rumbaut 1997: 4). La propuesta de análisis plantea abordar el objeto de estudio desde la dinámica interna de la vida familiar. Asimismo, es importante tomar en cuenta el contexto social y cultural del lugar de origen de las familias inmigrantes y el contexto de recepción.

\section{VIDA FAMILIAR}

Antes de entrar en materia sobre el análisis teórico de las aspiraciones educativas de los hijos de padres en México y Estados Unidos, es importante tomar en cuenta la definición del concepto de vida familiar y cómo será abordada, para ello hemos recurrido a distintas 
fuentes disciplinarias. Sin embargo, primeramente, es indispensable puntualizar el concepto de familia, también entendido como grupo doméstico. Sin lugar a duda existen evidencias cada vez más sólidas sobre la idea de que la familia campesina entendida como unidad de producción-consumo basada en la solidaridad de todos sus miembros ya no es posible sostenerse. Al respecto, Patricia Arias señala que:

Las familias han transitado, con enormes dificultades, ajustes y tensiones, hacia esquemas de reproducción económica que no corresponden a la noción de producción-consumo. Sin embargo, los cambios económicos antecedieron a todos los demás; la agricultura dejó de ser la actividad central de las familias campesinas y el ingreso asalariado adquirió la categoría de indispensable. En ese proceso de cambio económico, también laboral, los jóvenes, hombres y mujeres, ganaron protagonismo y visibilidad. Pero esa redefinición de los generadores tradicionales de ingresos se topó con enormes resistencias culturales. En general, las familias y las comunidades han rechazado, se han negado a aceptar que el cambio económico acarree modificaciones en las relaciones de generación y de género [...]. Las familias han tratado por todos los medios a su alcance, de mantener algún tipo de control sobre cónyuges, hijos e hijas. Aunque con cada vez menos éxito y más tensiones. Los cambios económicos han tocado dos ámbitos muy sensibles de las familias rurales: la solidaridad y el ciclo de desarrollo doméstico (Arias 2009: 33-34).

Por su parte, algunos autores como Wolf (1990) señalan que los estudios de los grupos domésticos en los países del tercer mundo parecen ser el único contexto en el cual el mito de la unidad familiar y la solidaridad es perpetuado, y esto se ve más claro en el concepto de las estrategias de los hogares. A lo que Arias advierte que:

Los estudios etnográficos recientes ofrecen evidencia suficiente para cuestionar la noción de estrategias familiares de reproducción donde la toma de decisiones se entendía como una decisión colectiva y consensuada para dar pie a una situación donde los diferentes miembros de los grupos domésticos, también las mujeres, buscan sacar adelante proyectos conyugales o personales. Aunque persistan vínculos y compromisos vigorosos entre los miembros de los grupos domésticos hay que aceptar que en este momento existe una 
Norteamérica y sus aspiraciones educativas: una nueva propuesta teórica

«menor influencia de las familias de origen y los parientes para delimitar las pautas de individualización e independencia que dan soporte a los núcleos individuales» (Esteinou 2009: 12). No sólo eso. Ya no es posible presuponer el contenido de las relaciones que establecen entre los miembros al interior de los grupos domésticos nada más porque comparten un hogar y viven en el espacio rural (Arias, en prensa).

Al respecto, Wolf asevera que «el concepto de estrategias del hogar tergiversa las conductas al interior del hogar, oscurece la estratificación por género y generación al interior del hogar, y ahoga las voces de los sin poder, que por lo general son las mujeres y los jóvenes» (1990: 44). Por lo anterior, no es posible ya sostener la idea de estrategias familiares sin analizar el proceso de la toma de decisiones en la familia, donde el hogar es tratado como «un individuo con otro nombre», como si tuviera intereses, con una lógica e intereses propios (Folbre 1986, citado en Wolf 1990: 46). Donde el comportamiento presentado por alguno de los miembros del hogar con frecuencia es interpretado como si fuera motivado por los intereses del hogar como un todo. Es así que

El individuo es tratado como un hogar en miniatura, como si estuviera dirigido por un gen de interés del hogar con cualquier y con todo comportamiento, lo que supone refleja las necesidades del hogar. Si bien, esta hipótesis representa un buen ejemplo de la solidaridad mecánica de Durkheim, es analítica y empíricamente problemática (Wolf 1990: 46).

Arias (en prensa) agrega que existen tres conjuntos de factores que han abonado a detonar cambios que han dado lugar a nuevos fenómenos y configuraciones de género: el desmantelamiento de los recursos, actividades y poderes tradicionales de los grupos domésticos, los cambios sociodemográficos y la emergencia de nuevos patrones migratorios. Pero estos factores que han motivado los cambios en las familias no solo se reducen a las zonas rurales, sino también a los grupos domésticos de las áreas urbanas.

Dicho lo anterior, es importante matizar que si bien las familias campesinas rurales no es posible caracterizarlas tácitamente como iguales que a las familias que residen en 
comunidades urbanas de larga tradición migratoria $\longrightarrow$ de otras áreas del país-, sin embargo, guardan una serie de elementos, reglas o valores, plasmados en prácticas, acciones y formas de organización concretas, que le son afines a las familias campesinas, en tanto, todos estos elementos se han puesto a prueba en sociedades más urbanas y con un mayor tinte de modernización, impactada por las comunicaciones, donde aunado a esto la migración ha permeado y modificado la dinámica de los hogares tradicionales basadas en relaciones de poder y desigualdad entre hombres y mujeres (Arias 2009). Mas sin embargo existen evidencias etnográficas donde se señalan que las modificaciones también han abarcado las dinámicas internas de los hogares tradicionales de las ciudades medias y pequeñas de larga tradición migratoria (Massey et al. 1991, Durand 1994), muestra de ello se refleja en las trasformaciones en la nupcialidad y la exogamia de sus pobladores (Durand y Martínez 1999, Martínez 2003, Martínez 2004). Aunque hay poca atención en los lentos cambios en las relaciones dentro del hogar, entre géneros y entre las generaciones (Wolf 1990), cada vez hay más evidencias empíricas al respecto (Ariza y Portes 2007, Cerrutti y Gaudio 2010). Además, «la migración aparece como una vía que las mujeres están aprovechando para modificar su condición desventajosa en los grupos domésticos, que es el ámbito donde se plasman los modelos de reproducción social rurales» (Arias 2009: 49), de igual manera esta situación está cada vez más presente en las familias de las zonas urbanas.

En ese contexto es importante señalar que el concepto de familia es un punto estratégico para el análisis del cambio en la vida de sus miembros - inmigrantes y no inmigrantes-, de ahí que las familias sean el principal y mayor grupo íntimo de reproducción y socialización; las familias, frecuentemente, sirven para movilizar trabajo, asignar recursos y son un agente de comunicación y cambio con otras sociedades de inmigrantes (Rumbaut 1997). Asimismo, se entiende la familia como un «crisol de independencia y socialización, con un carácter de conciencia, autoridad y disciplina de los propios integrantes de la misma, donde los une una cadena de sentido y significado». Pero, así como en la familia se pueden establecer fuertes lazos de solidaridad y cohesión social entre sus miembros, «también puede convertirse en el sitio para la práctica de intensos y profundos conflictos entre 
cónyuges, hermanos y padres e hijos, especialmente entre las familias inmigrantes quienes se mueven de un ambiente sociocultural a otro, entre roles generacionales y de género disonantes que cambian rápidamente las relaciones de pareja y de padres e hijos» (Rumbaut 1997: 8-9).

En ese sentido, la noción de vida familiar debe abordarse como las acciones que realizan los sujetos dentro de la dinámica interna de la familia, permeada por las relaciones entre padres e hijos, a partir de la cohesión familiar que establece cada familia y con base en la comunicación que los miembros de la misma instituyen, dado que los padres desarrollan estrategias para promover comportamientos en sus hijos acordes con sus expectativas, con los mecanismos que son utilizados para legitimar su autoridad moral y práctica, así como distintas formas que utilizan para inculcar una disciplina y los valores que orientan a la educación y la crianza de los hijos. Es decir, «las formas en que los padres ejercen sus roles como tales, lo cual forma parte de lo que ha sido denominado parentalidad» (Esteinou y Nehring 2009: 87). Esta serie de conceptos de familia y vida familiar ha sido estudiada por historiadores, antropólogos y sociólogos, a partir de los arreglos familiares y las relaciones paternofiliales referentes al comportamiento y los sentimientos en la vida diaria de la familia, así como al papel de los padres en el cuidado de los hijos, los estilos de crianza. También se ha estudiado la vida familiar a partir de las distintas formas en que se establece la formación de las familias; otro punto tomado en cuenta es la visión de los hijos sobre el papel de los padres, así como la etapa de la adolescencia, el cuidado y apoyo de los padres sobre la educación formal de los hijos. Asimismo, se ha visto a la familia no solo como unidad productiva de las personas, sino también como un vínculo directo entre las actividades económicas de las personas y la configuración de la familia que conforma el hogar.

Otro aspecto muy estudiado ha sido el referente a las distintas formas de la herencia y los patrones que se siguen de acuerdo con las diversas sociedades. Todos estos aspectos han sido abordados a través de las distintas etapas de la historia en distintas sociedades del 
mundo, sin embargo, en mi estudio abordaré sólo los temas relacionados con la educación formal y la importancia de los padres en la educación de sus hijos, y la de los propios hijos, temas que son fundamentales para el análisis del impacto de las aspiraciones educativas de los estudiantes de secundaria y bachillerato en los lugares de origen y destino.

\section{LA SEGUNDA GENERACIÓN EN ESTADOS UNIDOS: EDUCACIÓN Y ASPIRACIONES}

El tema de los hijos de los inmigrantes en Estados Unidos es un asunto que fue estudiado y analizado por primera vez por la Immigration Commission, que el Congreso de ese país convocó en febrero de 1907 con el fin de analizar el estado de la cuestión de los inmigrantes y sus hijos en aquel país, dirigida por el senador William P. Dillingham. En 1911 se publicaron los Reportes, documento donde se examinaron varios aspectos de la vida de los inmigrantes en la sociedad norteamericana. Este estudio contiene un apartado especial intitulado Reporte sobre los hijos de los inmigrantes en las escuelas, donde se detallan los pormenores de la situación de los hijos de los inmigrantes. Cabe mencionar que el reporte se centró en estudiar a los inmigrantes europeos y sus familias que arribaron entre 1819 a 1910 (Cordasco 1973), para esas fechas los mexicanos ya se habían hecho presentes en el gran flujo de inmigrantes, estaban básicamente concentrados en el suroeste y en la región de Los Grandes Lagos.

Para finales del siglo XIX y principios del XX, la escuela jugó un papel importante en la introducción de un modo de vida diferente, en tanto se consideró que su función esencial era la asimilación forzada de los hijos de los inmigrantes (Cordasco 1973). Para los inmigrantes de principios del siglo XX una parte integral en la experiencia social fue, sin duda, la enseñanza y la escolarización de sus hijos en Estados Unidos. Detrás de la preocupación por el aprendizaje de los hijos, estaba la aspiración primordial para emigrar al nuevo continente, el deseo de ganar más dinero y vivir mejor y, de ser posible, obtener riqueza y fama (Smith 1969). Desde entonces, el gobierno norteamericano ha hecho hincapié en el proceso de adaptación y asimilación de los inmigrantes y sus hijos. 
La adaptación y la asimilación son aspectos que no se han dejado de lado en la discusión teórica sobre el proceso que todo hijo de inmigrante transita hasta llegar a la adultez. Tal como aconteció con los hijos de inmigrantes europeos, una parte de la experiencia de la vida en la sociedad norteamericana de los hijos de inmigrantes mexicanos es, sin duda, la enseñanza y la escolarización.

Las aspiraciones educativas de los hijos de inmigrantes juegan un papel fundamental en su proceso educativo y sus aspiraciones educativas influyen en los resultados escolares (Sewell et al. 1969, 1970), y sientan la posibilidad de obtener un título universitario, lo que permitirá conseguir un empleo bien remunerado. Se ha dicho que tanto «los resultados educativos como los del mercado laboral representan la mejor medida del progreso de la segunda generación, ya que se trata de adaptarla a la sociedad americana» (Portes y MacLeod 1996: 256). Asimismo, se ha demostrado que uno de los mejores parámetros para predecir el éxito académico o la deserción escolar de los jóvenes pertenecientes a una minoría son las aspiraciones educativas (Kao y Tienda 1995, Rumberger 1983).

Las aspiraciones educativas son incluso importantes para vaticinar la orientación futura de los hijos de inmigrantes (Kao y Tienda 1998). Son varios los estudiosos que han explicado por qué algunos hijos de inmigrantes logran concretar sus aspiraciones y por qué otros no lo logran, sin embargo, son escasos los estudios que han explicado el papel de la familia en la formación de las aspiraciones. Asimismo, son muy pocos los trabajos que se hayan centrado en los hijos de los inmigrantes mexicanos y sus familias en ambos lados de la frontera (Smith 2006, Dreby 2010), para analizar la formación de las aspiraciones educativas. Desde esta perspectiva de análisis, este trabajo intentará contribuir a la discusión teórica.

\section{EL ESTUDIO DE LOS HIJOS DE MEXICANOS EN ESTADOS UNIDOS}

Hasta hace pocas décadas, el estudio de la inmigración contemporánea en Estados Unidos se había concentrado en estudiar a los propios inmigrantes sobre sus motivos para emigrar y 
sus modos de adaptación en el mercado laboral y en la sociedad de acogida. Es hasta mediados de los años sesenta del siglo XX cuando la atención se centró en la segunda generación. $^{2}$ La primera generación de inmigrantes siempre ha sido un grupo que permanece por un tiempo en el lugar de acogida y que, al día siguiente, puede cambiar de lugar, o simplemente regresar a su país de origen. Los inmigrantes de la primera generación son un grupo «en el país, sin llegar a ser del país. Por el contrario, la mayoría de sus hijos nacidos y criados en Estados Unidos están aquí para quedarse, son ciudadanos enteramente impregnados de la cultura y de las aspiraciones americanas» (Portes 2006: 21). De manera que los modos de adaptación de esta segunda generación van a jugar un rol decisivo a largo plazo en el destino de los grupos étnicos que la inmigración contemporánea ha creado (Portes y Rumbaut 1996, Zhou 1997). Además, la población escolar perteneciente a la segunda generación de inmigrantes mexicanos ha sido un segmento olvidado y merece ser tomado en cuenta para su análisis (Portes y MacLeod 1996).

El flujo de migración de mexicanos hacia Estados Unidos ha sido cada vez más intenso desde mediados de la década de los sesenta, tras la aprobación de la Ley de inmigración en 1965. ${ }^{3}$ A partir de esta fecha, varios estudiosos se interesaron en explorar a las minorías no blancas en Estados Unidos y a los latinos en particular. El trabajo de Leo Grebler, Joan Moore y Ralph Guzmán, realizado a finales de los sesenta y publicado en 1970 con el título The Mexican American People: The Nation's Second Largest Minority, detalla el proceso social de la adaptación y la asimilación de los inmigrantes de origen mexicano y sus descendientes que residían en el condado de Los Ángeles, California, y en la ciudad de San Antonio, Texas. En ese estudio, ellos concluyeron que, no obstante algunos sectores de la población mexicoamericana han entrado a la clase media y han comenzado a participar en la sociedad norteamericana, todavía hay en general poca asimilación, incluso para aquellos que han vivido en Estados Unidos durante varias generaciones (Grebler et al. 1970). Esta misma conclusión ha sido sostenida y fundamentada por trabajos posteriores como el de Telles y Ortiz (2008), convirtiéndose en uno de los referentes obligados de la teoría de la asimilación segmentada (Portes y Zhou 1993). 
La Ley IRCA (Immigration Reform and Control Act), promulgada en 1986, impulsó un mayor flujo de mexicanos, sobre todo de una migración de carácter familiar, y desde la última década del siglo XX el flujo de mexicanos se intensificó. El crecimiento de la segunda generación ha sido alimentado por dos procesos: el restablecimiento familiar y la alta fecundidad de los inmigrantes. Las primeras olas de inmigrantes estaban compuestas principalmente de hombres jóvenes en busca de oportunidades económicas: sin embargo, con el tiempo, estos hombres tienden a establecerse y a llevarse a los miembros de su familia. En un lapso corto la migración familiar se ha convertido en la norma, impulsada tanto por las redes familiares como por la ley que provee la reunificación familiar en Estados Unidos (Massey et al. 1991, Durand 1994, Portes y MacLeod 1996).

Conforme ha cambiado el perfil del inmigrante mexicano, también han ido cambiando las aspiraciones de los padres e hijos, así pues los inmigrantes más recientes traen consigo sus aspiraciones a su nuevo lugar de residencia, aspiraciones que también son trasmitidas a sus descendientes. Es quizá el estímulo y las aspiraciones una de las mayores influencias en la educación de los hijos por parte de sus padres inmigrantes (Fuligni 1997). Los nuevos inmigrantes de fines del siglo XX y principios del XXI emigran con un proyecto de vida que incluye a toda la familia (Martínez 2003). Aunque las familias llevan consigo un capital social y humano, además de habilidades que les serán de utilidad para lograr sus aspiraciones, también encontrarán obstáculos para lograr sus aspiraciones. Para explicar este proceso, es importante plantear una propuesta propia desde una perspectiva teórica que ayude a explicar y analizar la formación de las aspiraciones educativas de los hijos de inmigrantes mexicanos y que considere el contexto de las familias desde el origen.

\section{PERSPECTIVAS TEÓRICAS}

Las teorías que se han utilizado para explicar las aspiraciones educativas de los estudiantes pertenecientes a las minorías de ascendencia mexicana se han centrado principalmente en explicar los bajos niveles de éxito educativo, en relación con los estudiantes blancos no 
hispanos o de ascendencia asiática. Sin embargo, hoy por hoy el estudio de los hijos de inmigrantes revela una nueva información acerca de este segmento cada vez más importante de los jóvenes en edad escolar en Estados Unidos.

Las teorías que se han utilizado difieren en sus planteamientos. Algunas se centran en los estudiantes, sus familias o sus escuelas, y en el escenario para entender las aspiraciones educativas. Otras consideraciones teóricas más amplias focalizan su interés en el papel del estatus socioeconómico de la familia y de la comunidad étnica sobre el rendimiento académico individual (Portes y MacLeod, 1996). Podemos ubicar dos marcos teóricos generales sobre los factores determinantes de las aspiraciones, por un lado está el marco teórico tradicional «alcanzar el estatus», al que también se conoce como la perspectiva socioeconómica. Por otro lado, se ubica el modelo de «las oportunidades bloqueadas» conocido también como la perspectiva sociocultural. A pesar de las diferencias, ambas perspectivas de análisis comparten importantes apreciaciones sobre muchas percepciones complementarias que influyen en el proceso de formación de las aspiraciones educativas.

\section{PERSPECTIVA SOCIOECONÓMICA: EL MODELO «ALCANZAR EL ESTATUS»}

El proceso de formación de las aspiraciones educativas de los estudiantes ha sido ampliamente debatido desde el Wisconsin Research Program en 1957, cuando se realizó un estudio basado en la experiencia educativa de jóvenes varones blancos, en varias escuelas públicas y privadas de Wisconsin. Fue a partir de este proyecto que se desarrolló el modelo teórico denominado «Wisconsin Social Psychological Model of Status Attainment» o simplemente conocido como «Wisconsin Model» (Haller y Portes 1973; Alexander, Eckland y Griffin 1975), que tal vez fue el enfoque más comentado de la investigación en este ámbito (Sewell y Hauser 1980). Este modelo establece, por un lado, que el estatus socioeconómico (SES) de los padres tiene un fuerte efecto positivo en las aspiraciones y el éxito educativo de los estudiantes; por otro lado, postula que las expectativas y las normas que son significativas para los padres, profesores y para los estudiantes con quienes entran en contacto, tendrán un efecto positivo en las habilidades académicas de los estudiantes 
(Sewell y Shah 1968, Sewell y Hauser 1993).

Los padres y maestros forman las expectativas para el éxito futuro de los estudiantes sobre la base del rendimiento escolar relativo dentro de la escuela. Entre los estudiantes con notable rendimiento académico, los padres y maestros desarrollan altas expectativas; por el contrario, para aquellos que tienen pobre rendimiento académico, los padres y profesores forman bajas expectativas. Así, las expectativas de padres y docentes ejercen una fuerte influencia en las aspiraciones de los propios estudiantes, realzando las aspiraciones y expectativas de algunos y reduciendo las de otros (Sewell, Haller y Ohlendorf 1970). Sin embargo, entre las minorías el efecto significativo de los otros debe ser entendido de acuerdo con su sistema de creencias, valores y estrategias de acción dentro de la actual estructura social y de la desigualdad económica y social (Goyette y Xie 1999, Ogbu y Simons 1998). Las aspiraciones educativas de los padres y de los estudiantes pueden ser determinadas por las actitudes y las percepciones de padres y estudiantes sobre el papel de la educación en el progreso económico y social del grupo, y por sus percepciones de las oportunidades disponibles para el éxito en el sistema educativo y el mercado de trabajo (Ogbu 1992).

Las primeras exploraciones de las aspiraciones educativas y ocupacionales intentaron explicar las variaciones sobre la base de las diferencias individuales de los miembros de las distintas clases sociales entre los blancos americanos. Los indicadores del estatus socioeconómico de la familia - en particular, la educación y la ocupación de los padres y el ingreso familiar - vaticinan de manera significativa el nivel de educación de los hijos y otras variables del capital humano que, a su vez, predicen el nivel ocupacional y de ingresos de los hijos. Estos estudios han revelado los efectos desiguales sobre las aspiraciones educativas y ocupacionales (Sewell 1971).

Por otra parte, Kao y Tienda (1998) señalan que las diferencias étnicas y raciales en las aspiraciones educativas simplemente reflejan la inequidad socioeconómica entre los 
jóvenes de las minorías y de las no minorías. Esto es así porque los estudiantes blancos tienen en promedio más recursos que los estudiantes negros o hispanos; lo que supone que los jóvenes blancos podrían tener más altas aspiraciones educativas que sus compañeros negros o hispanos. Los recursos socioeconómicos de los estudiantes blancos y asiáticos son similares, en tanto sus aspiraciones educativas también podrían ser similares. Implícitamente, esta lógica rechaza el efecto de las diferencias de raza y etnia en las motivaciones para alcanzar el éxito, así como en la variación de los planes educativos que se derivan exclusivamente de las diferencias sociales —educativas - y de los ingresos —económicos - de los padres. Kao y Tienda (1998) también señalan que las barreras estructurales a los recursos sociales, a las creencias y a las prácticas culturales, diversifican las aspiraciones educativas a lo largo de la línea de la raza y la etnia, más allá de los patrones pronosticados por los orígenes familiares y el acceso a los recursos materiales.

El análisis de las tendencias en las aspiraciones y el éxito educativo sugiere que el proceso de estratificación difiere según la raza y los estratos sociales a los que pertenezca el estudiante. Asimismo, postula que las tendencias entre los estudiantes negros son inestables (Garrison 1982, Hauser y Anderson 1991) y, muy seguramente, las tendencias entre los estudiantes hispanos también serán inestables. Varios estudios contemporáneos sobre la integración de los inmigrantes consideran que los mexicoamericanos están en desventaja y que les toma mucho tiempo asimilarse debido al bajo capital humano de sus padres (Bean y Stevens 2003, citado en Telles 2008).

El modelo «alcanzar el estatus», que inicialmente fue elaborado para ser aplicado únicamente en jóvenes de raza blanca — menos de $2 \%$ de la muestra realizada en Wisconsin—, estuvo representado por la población afroamericana (Sewell y Hauser 1993), posteriormente fue planteado en varios grupos raciales y étnicos. Este modelo plantea que mientras los estudiantes altamente calificados tienen acceso a las redes de profesionistas y a la institución dominante, por lo que sus carreras escolares pueden ser exitosas, sin embargo el éxito de los estudiantes no blancos puede ser obstaculizado en la medida que no cuentan 
con esos recursos.

En este sentido Warren (1996), en un estudio sobre la inequidad educativa entre estudiantes blancos e hijos de inmigrantes de origen mexicano, encontró que los factores del origen socioeconómico familiar son los que mayormente explican la posición de desventaja educativa entre los adolescentes de descendencia mexicana en relación con los adolescentes blancos no latinos. De acuerdo con los distintos estudios analizados pareciera que el significado y el efecto del estatus socioeconómico varían según el grupo étnico que se analice, también se ubican investigaciones que cuestionan si las diferencias en el estatus socioeconómico de las familias son suficientes para explicar el gran hueco en el éxito educativo entre los estudiantes latinos y asiáticos.

Por su parte, Portes y MacLeod (1996) llegaron a la conclusión de que los estudiantes de la segunda generación no son diferentes de aquellos con padres nacidos en Estados Unidos quienes, en gran medida, son influenciados por su estatus socioeconómico familiar y por el nivel socioeconómico promedio de sus escuelas. Además revelaron que:

[...] los factores que explican la significativa diferencia entre estos grupos -cubanos, mexicanos, haitianos y vietnamitas - tienen que ver con el capital humano que los inmigrantes traen consigo desde sus países de origen, con el contexto social que los recibe, y con la forma de adaptación en los Estados Unidos. [...] Las diferencias en los modos de incorporación influyen en el subsecuente desarrollo de las comunidades de inmigrantes (Portes y MacLeod 1996: 271).

Con base en los estudios empíricos mencionados, podemos afirmar que la situación socioeconómica de la familia no es suficiente para explicar el rendimiento escolar, el proceso de formación de las aspiraciones y el éxito educativo de los hijos de inmigrantes de origen mexicano, por ello es indispensable orientar la investigación hacia los efectos que conlleva la dinámica familiar en las aspiraciones de los hijos de inmigrantes. 


\section{PERSPECTIVA SOCIOCULTURAL: EL MODELO «LAS OPORTUNIDADES BLOQUEADAS»}

El enfoque de las oportunidades bloqueadas es un intento por responder y explicar las diferencias en los resultados educativos entre las minorías y las no minorías, esta perspectiva también es relevante para entender las aspiraciones educativas y las diferencias de raza y etnia (Kao y Tienda 1998). Al igual que el modelo alcanzar el estatus, este enfoque también ha intentado estudiar el rendimiento escolar, las aspiraciones y el éxito educativo, Sin embargo, Ogbu (1992) señala que estos aspectos fundamentales en la educación de los hijos de las minorías en Estados Unidos pueden ser explicados más completamente en términos de los factores socioculturales, así como de las fuerzas de la comunidad y el contexto de recepción de los grupos minoritarios en aquel país.

Ogbu propone una visión sociocultural para explicar por qué los estudiantes de las minorías tienen un rendimiento menos favorable en la escuela, que los estudiantes de las mayorías. Esta perspectiva es un enfoque centrado, en primer término, en el escenario, entendido como el «medio ambiente», o «el mundo» de las personas — de las minorías - y, en segundo término, en lo cultural, que en sentido amplio refiere la manera como la gente ve el mundo y su comportamiento en consecuencia (Ogbu y Simons 1998). Estos aspectos deben tomarse en cuenta para el análisis de la vida familiar y sobre la forma cómo los integrantes de la familia ven el mundo y por qué se comportan de determinada manera al tomar decisiones relacionadas con el plano educativo y al analizar el proceso de adaptación en la sociedad donde se incorporan.

La búsqueda de una explicación del rendimiento escolar se inició en 1968 con el estudio realizado en Stockton, California, con estudiantes afroamericanos y de ascendencia mexicana. Ogbu y Simons (1998: 155) llegaron a la conclusión de que «las diferencias fueron causadas por el trato de los grupos minoritarios en la sociedad en general y la escuela, así como por las percepciones de las minorías y sus respuestas a la escuela, debido a dicho trato». En la década de 1980 el centro de la investigación cambió hacia la explicación de las diferencias en el rendimiento escolar entre los propios grupos 
minoritarios, analizando las barreras estructurales de la educación en las minorías, centrándose en las fuerzas de la comunidad, uno de los dos aspectos que influyen en la educación de las minorías, las cuales son producto de la adaptación sociocultural y se encuentran dentro de la comunidad minoritaria (ver Cuadro 1).

Cuadro 1. Las dos partes del problema de la enseñanza de las minorías

\begin{tabular}{|c|l|}
\hline El Sistema & \multicolumn{1}{c|}{ Las fuerzas de la comunidad } \\
\hline \multirow{2}{*}{$\begin{array}{c}\text { Educación Social } \\
\text { Políticas y Prácticas }\end{array}$} & $\begin{array}{l}\text { Doble marco de estatus de referencia } \\
\text { Creencias instrumentales sobre la } \\
\text { interpretación de la enseñanza. (Función de } \\
\text { los títulos universitarios para el avance } \\
\text { personal) }\end{array}$ \\
\cline { 2 - 3 } $\begin{array}{c}\text { Recompensas sociales por el } \\
\text { logro educativo de la verificación } \\
\text { de los títulos universitarios }\end{array}$ & $\begin{array}{l}\text { Creencias relacionadas con la interpretación } \\
\text { de la enseñanza (Nivel de confianza y control } \\
\text { de la escuela, la enseñanza como un sistema } \\
\text { de subordinación y control) }\end{array}$ \\
\hline \multirow{2}{*}{$\begin{array}{c}\text { El trato de las minorías } \\
\text { en la escuela }\end{array}$} & $\begin{array}{l}\text { Creencias sobre la interpretación simbólica de } \\
\text { la enseñanza. ¿Es el aprendizaje curricular, las } \\
\text { prácticas culturales y de lenguaje en la } \\
\text { escuela, una amenaza para la identidad de las } \\
\text { minorías culturales y lingüísticas? }\end{array}$ \\
\hline Adaptación social y rendimiento académico \\
\hline Minoría, estrategias educativas \\
\hline
\end{tabular}

Fuente: Este cuadro está basado en la teoría ecológica cultural del desempeño escolar de las minorías, elaborada por John Ogbu (Ogbu y Simons 1998: 156).

El estudio de las fuerzas de la comunidad implica el análisis de las percepciones y las respuestas de las minorías a la educación que da el Estado. Cuatro factores son los que 
constituyen las fuerzas de la comunidad: un marco de comparación de las escuelas de las minorías, las creencias sobre el valor instrumental de la escuela, las interpretaciones relacionales de la enseñanza - por ejemplo, el grado de confianza de las escuelas y del personal de la escuela—, y las creencias simbólicas acerca de la enseñanza — por ejemplo, si el plan de estudios de aprendizaje de la escuela y del idioma se consideran nocivos para la identidad de las minorías culturales y lingüísticas (Ogbu y Simons 1998).

De acuerdo con la teoría ecológica cultural de Ogbu, el trato de las minorías en la sociedad en general se refleja en su tratamiento en la educación. Este planteamiento adopta tres formas, todo lo cual afecta la adaptación escolar y el rendimiento escolar (ver Cuadro 1). El primer punto son las políticas generales y las prácticas educativas hacia las minorías — por ejemplo, la política de segregación escolar, financiamiento desigual de la educación y del personal que atiende las escuelas de las minorías, etc.- . El segundo es la recompensa, o la falta de ellas, que la sociedad da a las minorías por sus diplomas obtenidos en la escuela, especialmente en el empleo y los salarios. El tercero es cómo los estudiantes de las minorías son tratados en las escuelas y en los salones de clase - por ejemplo, el nivel de expectativas de los maestros, los patrones de interacción profesor-estudiante, agrupación y separación, etc.- Cabe destacar que todas las minorías estudiadas por Ogbu han experimentado estos tratamientos discriminatorios.

Ogbu (1983) define el estatus de minoría sobre la base de las relaciones de poder entre los grupos y no en términos de representación numérica. Una población es una minoría si ocupa algún tipo de posición de poder subordinado en relación con otra población dentro del mismo país o de la misma sociedad. Para entender el proceso de adaptación de las minorías y la comprensión de las barreras estructurales que limitan la educación de los miembros de los distintos grupos minoritarios en Estados Unidos, Ogbu las divide en minorías autónomas, voluntarias e involuntarias.

Según Ogbu, las minorías autónomas están representadas en Estados Unidos por grupos 
como los amish, judíos, y mormones; son principalmente minorías en un sentido numérico, por lo que no están totalmente subordinadas al grupo dominante política o económicamente. En general, las minorías autónomas pueden tener una identidad distintiva racial, étnica, religiosa, lingüística o cultural que está garantizada por la Constitución nacional o por la tradición. Pueden ser víctimas de prejuicios, sin estar subordinadas a un sistema de estratificación rígida. A menudo, esas minorías tienen un marco cultural de referencia que alienta y demuestra éxito. Al menos en Estados Unidos, las minorías autónomas no se caracterizan por el fracaso escolar desproporcionado y persistente.

Las minorías voluntarias son las personas que han emigrado más o menos voluntariamente a la sociedad de acogida:

[...] porque desean más el bienestar económico, en general mejores oportunidades, y/o una mayor libertad política. Las expectativas siguen influyendo en la manera en que perciben y responden a los acontecimientos, como la educación en la sociedad de acogida. Las minorías voluntarias suelen tener problemas iniciales en la escuela debido a las diferencias culturales y a las diferencias en el idioma, así como la falta de comprensión de cómo funciona el sistema educativo (Ogbu 1992: 8).

En un principio ellos pueden ocupar el peldaño más bajo de la escala ocupacional, con falta de poder político y poseer poco prestigio. Sin embargo, esta situación objetiva y estructural no refleja la totalidad de su estatus en la jerarquía social porque los inmigrantes no pueden subjetivamente pensar en su posición de la misma forma que lo hacen sus anfitriones. Los inmigrantes pueden considerar incluso que sus posiciones serviles son mejor que las que se tenían antes de emigrar (aunque no siempre suceda esta situación). Pueden ser objeto de la discriminación, pero por lo general no tienen tiempo para interiorizar los efectos de la misma o tienen los efectos arraigados como parte de su cultura (Ogbu 1983: 169).

Otro rasgo distintivo de las minorías voluntarias es la ubicación de su grupo de referencia. 
Tanto las minorías autónomas como las voluntarias miran a los miembros ricos del grupo dominante, sin embargo, su grupo de referencia son sus propios compañeros que se quedaron atrás, en su «patria» o en los barrios de inmigrantes. Es con ellos con quienes se comparan, encontrando a menudo muchas evidencias de su propio automejoramiento y de las buenas perspectivas para sus hijos como resultado de las «mejores oportunidades». Su más o menos voluntaria inmigración suele estar motivada por un deseo de acumular riqueza u otros medios para lograr la autopromoción «de vuelta a casa», no tienen un deseo por competir por el estatus de igualdad con los miembros de la élite de la sociedad de acogida. Esto, con frecuencia, actúa como un fuerte incentivo para explotar las oportunidades previstas y no previstas y para mantener actitudes instrumentales hacia las oportunidades económicas y educativas, incluso frente a los prejuicios y la discriminación.

Los inmigrantes voluntarios tienen por lo menos una opción simbólica de regresar a su «patria» o volver a emigrar a otro lugar si las condiciones se vuelven intolerables, pero la opción de regresar está más disponible para ellos que para las minorías involuntarias. Los inmigrantes de las minorías voluntarias por lo general no son caracterizados por una persistente desproporción de fracaso escolar. Para Ogbu, en Estados Unidos estas minorías incluyen a los chinos, cubanos, filipinos, japoneses y coreanos, entre otros. ${ }^{4}$

Las minorías involuntarias están en la parte opuesta de las minorías autónomas. A diferencia de los inmigrantes voluntarios, las minorías como castas o involuntarias, por lo general, han sido incorporadas en las sociedades de acogida más o menos de forma involuntaria y permanente. Su único medio de escape desde una posición tan involuntaria y permanente es «pasar» o emigrar - por rutas no siempre abiertas - al grupo de las minorías voluntarias. Los afroamericanos son un buen ejemplo de estas minorías: fueron traídos a América como esclavos y después emancipados y relegados a un estatus de casta, mediante mecanismos y dispositivos legales y extralegales. Los indios nativos, los mexicoamericanos y los puertorriqueños, también comparten con los afroamericanos la experiencia de incorporación involuntaria y el descenso de su estatus. Los indios, los 
dueños originales de la tierra, fueron conquistados y luego obligados a permanecer en reservas; los mexicoamericanos fueron conquistados y desplazados del poder en el suroeste, a quienes emigraron posteriormente desde México se les atribuía la condición de subordinación como el mismo grupo de conquistados. Los puertorriqueños están convencidos de ser parte de una colonia, tanto en Puerto Rico como en el continente (Ogbu y Simons 1998).

La pertenencia a un grupo minoritario como casta con frecuencia es permanente y adquirida al nacer. Esto es, sin embargo, mucho menos cierto para los indios, los mexicoamericanos y los puertorriqueños que para los negros, en parte por la amplia serie de diferencias de color dentro de cada grupo, que varían desde el puro blanco a puro negro. La variación en el color permite a los miembros de las minorías «pasar» al grupo dominante con el fin de superar las barreras de casta en la vida social, política y en las posiciones ocupacionales. En general, el tratamiento de los mexicoamericanos y los puertorriqueños depende más de su apariencia física que de su clasificación oficial como blanco...

[...] Al igual que las minorías como castas en todas partes, los negros, los indios, los mexicoamericanos y los puertorriqueños tradicionalmente se han considerado por el anglo blanco como inferiores y ocupan puestos más bajos que los blancos en todos los aspectos deseables. Ellos tienden económicamente a ser relegados a trabajos de baja categoría, situación que se utiliza para argumentar que se trata de una naturaleza favorable para su bajo estatus [...] Esta minoría como casta tiene una experiencia escolar de fracaso desproporcionado (Ogbu 1983: 171-172).

El mismo autor señala que esta tipología es válida para los inmigrantes que llegaron a Estados Unidos antes de 1965. En ese sentido, plantea que la tipología no es estática, algunas fuerzas internas y externas pueden cambiar la situación de un grupo minoritario determinado. Bajo el impacto de la urbanización, la industrialización, y la ideología igualitaria, los grupos de las minorías como castas «cada vez más se dirigen a la emancipación de las funciones tradicionales de baja categoría y a la igualdad con el grupo 
dominante. Algunas minorías pueden llegar a asimilarse al grupo dominante, pero la asimilación no es el objetivo de todas las minorías» Ogbu (1983: 172).

La perspectiva de las oportunidades bloqueadas ayuda al esclarecimiento de la formación de las aspiraciones, pero es incompleta. Una deficiencia es que la clasificación binaria de los jóvenes de las minorías es demasiado simplista (Kao y Tienda 1998). Por ejemplo, no está claro si los jóvenes refugiados deben ser considerados inmigrantes voluntarios o minorías involuntarias. Debido a la situación de los refugiados, algunos grupos presentan características de ambos tipos de minorías; la tipología de Ogbu no se puede acomodar fácilmente a sus experiencias o generar predicciones claras sobre la formación de la aspiración. De hecho, un defensor del marco de las oportunidades bloqueadas admitió que la situación de los refugiados políticos, los trabajadores invitados y los extranjeros ilegales, difiere significativamente de los inmigrantes voluntarios con estatus de residente permanente (Gibson 1991: 359, citado en Kao y Tienda 1998).

Es importante señalar que las expectativas y aspiraciones de los nuevos inmigrantes mexicanos de fines del siglo XX y principios del XXI ya no cuentan con las mismas expectativas de los inmigrantes que llegaron antes de 1965. Si tomamos en cuenta los cambios suscitados en las nuevas generaciones de inmigrantes mexicanos es difícil retomar tácitamente la tipología de Ogbu, pues si los nuevos inmigrantes mexicanos son catalogados como minorías voluntarias, tendríamos que tomar en cuenta también las características de las minorías involuntarias.

En este último sentido, las familias mexicanas en California pueden ser descritas como minorías voluntarias, con excepción de dos aspectos importantes; uno tiene que ver con el trato discriminatorio que sufren los inmigrantes mexicanos y sus descendientes en la escuela y en la sociedad en general. El otro aspecto está relacionado con el hecho de que los inmigrantes mexicanos tienen una experiencia escolar de fracaso desproporcionado a diferencia de los inmigrantes japoneses, chinos, vietnamitas o cubanos, quienes presentan 
niveles importantes de éxito educativo. Por lo anterior, no es indispensable tomar en cuenta la tipología de las minorías de Ogbu, no obstante sí es importante tomar las características de las minorías descritas por este autor para tratar de explicar el sistema y las fuerzas de la comunidad, factores que son sustanciales en el proceso de enseñanza y en la formación de las aspiraciones educativas de los hijos de inmigrantes en Estados Unidos.

Ogbu (1998) también señala que la falta de aceptación social de las minorías subordina y limita su integración en la sociedad dominante — lo que se refleja en el limitado éxito económico y laboral de los padres-, lo cual produce una cultura de oposición que reduce sus aspiraciones. Por lo tanto, la versión negativa del modelo de las oportunidades bloqueadas predice que los afroamericanos y los miembros de otras minorías tienen bajas aspiraciones educativas, en tanto no esperan que el éxito educativo produzca éxito económico.

Este proceso ha sido ampliamente documentado por MacLeod (2008), quien ilustra cómo las aspiraciones educativas de los jóvenes desfavorecidos son destruidas por sus experiencias cotidianas en la escuela, la calle y la casa. Pero, a diferencia de Ogbu y sus colegas, MacLeod no considera que la condición de minoría per se reduzca los niveles de aspiraciones educativas, sino más bien señala que los niveles de aspiraciones educativas se deben a las limitadas oportunidades que producen las desventajas que tienen las minorías.

\section{PROPUESTA DE MARCO TEÓRICO ALTERNO}

Algunos autores, al tratar de responder a la pregunta ¿por qué existen diferencias en el éxito académico entre los distintos grupos minoritarios en Estados Unidos?, encontraron que había que contemplar otros aspectos que no estaban presentes en el modelo alcanzar el estatus, ni en la perspectiva de las oportunidades bloqueadas, para explicar el proceso de formación de las aspiraciones y el éxito educativo de los hijos de las minorías, en especial, el caso de los hijos de inmigrantes mexicanos. Portes y Zhou (1993) y Portes y MacLeod (1996) al comparar varios grupos de inmigrantes asiáticos y latinos refinan la teoría 
sociocultural, enfatizando el proceso de incorporación social y el contexto de recepción en Estados Unidos $^{5}$ (véase también Portes y Zhou 1993, Portes y Rumbaut 1996).

El concepto de los modos de incorporación proporciona un instrumento teórico útil para comprender la diversidad y la vulnerabilidad de los recursos que afectan al proceso de adaptación de los hijos en la sociedad norteamericana. Los modos de incorporación están conformados por las políticas del gobierno del país anfitrión, los valores y los prejuicios sobre las minorías y las características de la comunidad étnica (Portes y Zhou 1993). Estos factores van a tener un papel relevante en las formas de adaptación de los hijos de inmigrantes en el lugar de establecimiento.

El contexto al que arriban los inmigrantes y sus hijos en Estados Unidos ha cambiado drásticamente en los últimos años: la brecha entre ricos y pobres se ha incrementado desde las últimas décadas del pasado siglo XX. Al mismo tiempo, la situación de los trabajadores norteamericanos ha empeorado, su movilidad económica se ha reducido y el número de pobres en este grupo, entre los cuales se cuentan a inmigrantes nacionalizados o de segunda generación, se ha incrementado. Con excepción de los inmigrantes con altos grados escolares y los altamente calificados, la condición de la mayoría de los inmigrantes mexicanos es bastante sombría. Las oportunidades de empleo estable con ingresos decorosos son cada vez más escasas para quienes tienen bajos grados de calificación. A los miembros de esta gran masa de pobres no se les ofrecen oportunidades para el mejoramiento socioeconómico, sino que fueron, en su mayor parte, alimentados, alojados y mantenidos en su limbo social y económico (Zhou 1997). Estas circunstancias se agravaron con la reciente crisis financiera y económica del año 2008.

Más allá de los elementos que entran en juego en las dos perspectivas teóricas ya mencionadas, es necesario agregar que el contexto social y cultural del lugar de origen de las familias inmigrantes es un elemento que no contempla ninguna de las dos perspectivas, ya que es fundamental tomarse en consideración para tener una visión más completa del 
proceso que viven las familias y sus hijos.

Por otra parte, un elemento más a considerar para el análisis tiene que ver con el capital social, el cual influye en las aspiraciones educativas de la mayor parte de los estudiantes, a través de las normas, los valores y las expectativas de los padres. Los estudiosos del tema han encontrado que el capital social de los padres desempeña un papel importante en el sistema educativo y en las oportunidades del mercado laboral de sus hijos. Por lo que las aspiraciones de los estudiantes tienden a desarrollarse a través de fuertes lazos entre los padres e hijos, que se traducen en normas, valores y en las percepciones sobre la importancia de la educación superior en relación con las oportunidades de la estructura social.

Tal como lo han indicado Hao y Bonstead-Bruns (1998) y Marjoribanks (1998), para que las expectativas y las normas de los padres se trasmitan a sus hijos es necesario que existan fuertes lazos dentro de la familia, lo que generará capital social. Estos autores han encontrado que los estudiantes que forman parte de familias en las que se mantienen fuertes vínculos entre padres e hijos, que son ricas en capital social, son más propensos a desarrollar altas aspiraciones sobre su futuro y tienen ambiciosos planes educativos. ${ }^{6}$

Asimismo, han demostrado que entre las minorías el capital social de la familia es uno de los factores más importantes en la formación de las aspiraciones de los hijos. Los resultados revelan claramente que el comportamiento de los estudiantes de las minorías en la escuela y sus opiniones acerca del éxito educativo, que son parte del capital social, y, en menor grado, su situación socioeconómica, ejercen una influencia significativa en sus aspiraciones. Pareciera que una cantidad significativa de la influencia de la adaptación en la escuela y del origen socioeconómico es mediada por el capital social de la familia y por las opiniones de los estudiantes (Khattab 2003). Una conclusión de estos trabajos es que el capital social de las familias de las minorías desempeña un papel importante en las aspiraciones de los hijos, tal como lo señalan Morgan (1996) y Kao y Tienda (1998) el 
capital social es un canal para la trasmisión de los valores, las normas, el conocimiento y las expectativas de los padres hacia sus hijos.

La propuesta teórica se centra en utilizar la categoría de capital social para explicar y analizar el impacto de la vida familiar en las aspiraciones educativas de los hijos de mexicanos en Estados Unidos y en México. Sin embargo, es indispensable considerar los estudios que señalan que no es suficiente tomar en cuenta el entorno social y económico, hay que considerar la probabilidad subjetiva del éxito educativo y el sistema de valores y creencias con respecto a la educación (Breen y Goldthorpe 1997, Garcia Coll y Magnunson 1997, Ogbu y Simona 1998). Estos estudios aseveran que la manera en que los estudiantes de las minorías perciben la realidad social y económica y sus oportunidades dentro del sistema educativo y del mercado laboral, es crucial en la determinación de desarrollar aspiraciones altas o bajas, situación que debe analizarse en las familias mexicanas en ambos lados de la frontera.

A pesar de las limitaciones de estas perspectivas teóricas que han intentado explicar la formación de las aspiraciones y el éxito educativo de los hijos de inmigrantes, han proporcionado una serie de elementos útiles que ayudan a explicar dicho proceso. Elementos que serán de gran utilidad para generar una propuesta de análisis para el caso de los hijos de inmigrantes mexicanos en Estados Unidos. Para ello, se propone combinar ambas perspectivas, agregando una serie de nuevos elementos tales como el contexto sociocultural del lugar de origen, las relaciones paternofiliales, los estilos de crianza, la preocupación de los padres por la educación y la importancia de la educación para el hijo. Estos elementos serán de gran relevancia para explicar el papel de la vida familiar en la formación de las aspiraciones educativas de los hijos de inmigrantes mexicanos en Estados Unidos. Dichos elementos son descritos en el esquema del Cuadro 2. 
Cuadro 2. Esquema teórico para la explicación de las aspiraciones y el éxito educativo de hijos de migrantes amequenses en California.

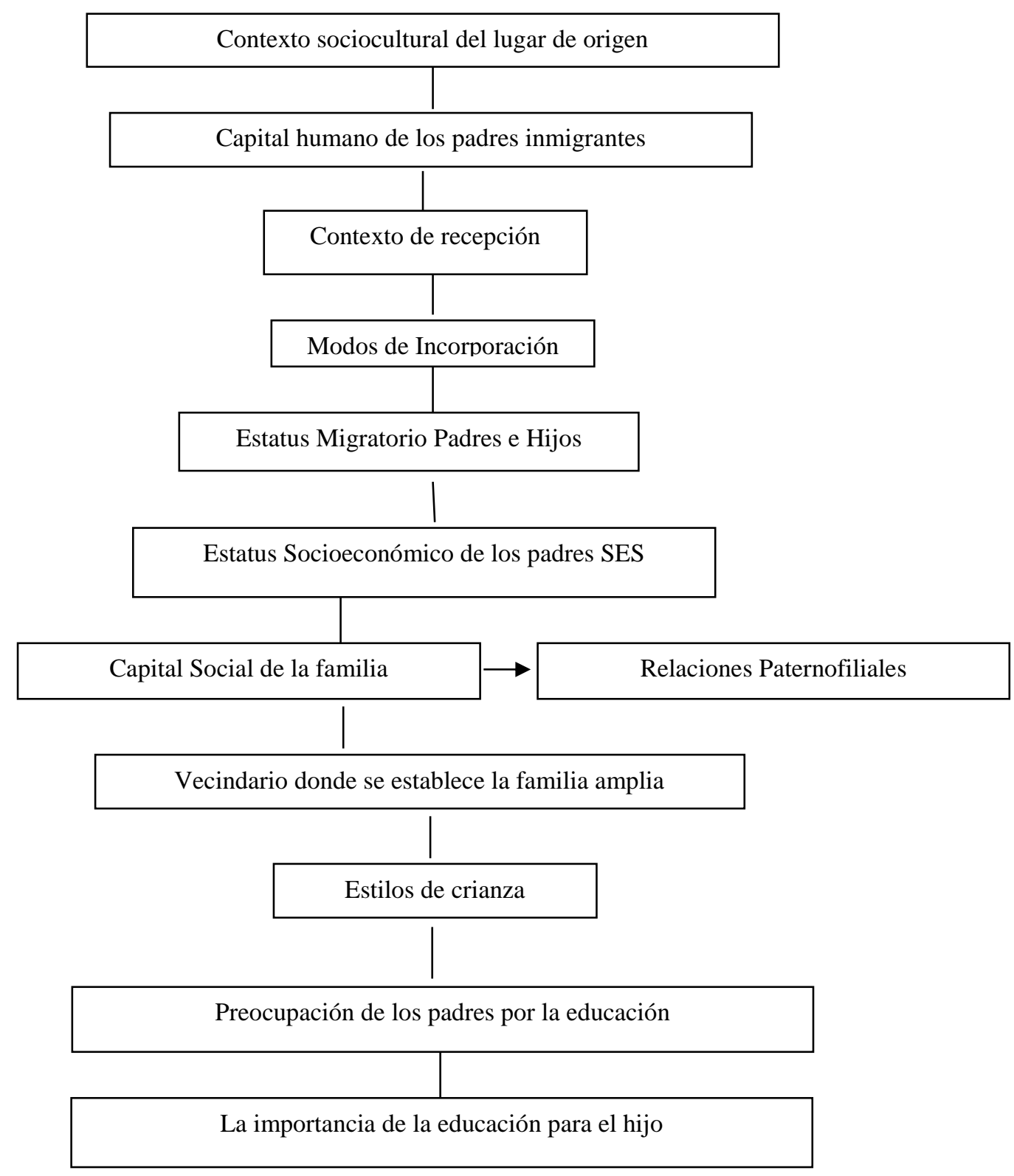

\section{ASIMILACIÓN SEGMENTADA}

Por su parte, la tesis de la asimilación segmentada provee otro marco teórico para examinar 
los diversos resultados sobre la segunda generación de migrantes. Portes y Zhou (1993) observan que la asimilación continúa sirviendo como una norma para la adaptación de los inmigrantes. Estos autores usaron el concepto de asimilación segmentada para referirse a las diferencias en las oportunidades de tener éxito entre inmigrantes de la segunda generación (Portes y Zhou 1992).

Tal como se plantea en innumerables artículos académicos y periodísticos, la expectativa es que la primera descendencia nacida en el extranjero después de ser asimilada busque la aceptación entre los nativos como un requisito para su movilidad social y económica. De no lograr esto quedarán confinados a las clases subordinadas. Esta idea de la movilidad social y económica tan arraigada en el pensamiento de los norteamericanos de clase media es seriamente cuestionada en la actualidad por el contexto desfavorable que hoy se vive en aquel país. Una mirada atenta de las experiencias de los inmigrantes mexicanos indica que la asimilación que viven estas poblaciones tiene un carácter segmentado. En este sentido, podemos preguntarnos ¿qué grupo particular de inmigrantes tiene posibilidades reales para asimilarse a la sociedad norteamericana? Una posición reproduce la antigua representación de la creciente aculturación y la integración de los inmigrantes a la clase media blanca; una segunda posición plantea que los inmigrantes están condenados a la pobreza permanente y a la asimilación a la clase baja; una tercera asocia el rápido avance económico con la preservación deliberada de los valores de la comunidad inmigrante y la solidaridad restringida.

Los posibles factores determinantes que influyen en la adaptación de los inmigrantes van desde los individuales hasta los estructurales. Entre ellos encontramos la educación, las aspiraciones, la habilidad en el idioma inglés, el lugar de nacimiento, edad de llegada y tiempo de residencia en Estados Unidos. Los factores estructurales son: el estatus racial, origen socioeconómico de la familia, y lugar de residencia. Los distintos modelos de asimilación especifican también estos dos conjuntos de variables. En ese sentido, es importante considerar que las perspectivas asimilacionista, multicultural y estructural se 
han enfocado a similares cuestiones desde diferentes puntos de vista. Los asimilacionistas se centran en los cambios que un nuevo entorno puede provocar en los patrones culturales y describen cómo los inmigrantes y sus generaciones venideras abandonan progresivamente las formas de su antiguo país. Los multiculturalistas reconocen que los patrones culturales originales de los inmigrantes constantemente se reforman y se reinventan a sí mismos, como ha sido la tradición, una parte indispensable para integrarse a la sociedad norteamericana y, por lo tanto, nunca pueden desaparecer por completo. Los estructuralistas hacen hincapié que en la medida en que los inmigrantes adopten formas del país de acogida, los beneficios de la adaptación dependen de la forma de la estructura social y económica del país de acogida (Zhou 1997). Sin embargo, la teoría de la asimilación segmentada se separa del marco teórico clásico con respecto a los efectos de estas determinantes, la cual supone que estos dos conjuntos de factores tienen en sí mismos una importancia mínima que se concentra en la interacción entre ambos (Zhou 1997).

El argumento principal de los promotores de la teoría de la asimilación segmentada era que la imagen de un camino de asimilación uniforme no hacía justicia a lo que estaba ocurriendo sobre la vida de los jóvenes hijos de inmigrantes en la actualidad. En cambio, el proceso se había convertido en caminos distintos segmentados, algunos lideraban hacia arriba pero otros hacia abajo. Los resultados reflejaban la alternativa de las barreras a la adaptación, encontrados por los jóvenes de la segunda generación en Estados Unidos y los recursos sociales y económicos se confrontaban para hacer frente entre ellos mismos con lo que sus familias poseen (Portes y Zhou 1992).

Este patrón de asimilación segmentada plantea, ¿cuáles son los factores que propician que algunos grupos de inmigrantes terminen en la pobreza y otros la eviten? (Portes y Zhou 1993: 82). Este modelo ha promovido un marco alternativo para profundizar en el complejo proceso de adaptación de los inmigrantes en Estados Unidos. La teoría de la asimilación segmentada se interesa por entender por qué surgen patrones de adaptación entre los inmigrantes contemporáneos y cómo estos patrones conducen necesariamente a distintos 
caminos de convergencia o divergencia. La teoría trata de explicar los factores que determinan la asimilación a la sociedad norteamericana de un grupo de inmigrantes en particular (Zhou 1997). Por su parte, en el siguiente Cuadro 3 podemos observar las fases de la movilidad a través de las generaciones a partir del modelo de la asimilación segmentada.

Cuadro 3. Fases de la movilidad a través de las generaciones: un modelo.

\begin{tabular}{|c|c|c|c|}
\hline Determinantes & Primera generación & Segunda generación & $\begin{array}{l}\text { Tercera generación } \\
\text { y más a fondo }\end{array}$ \\
\hline $\begin{array}{l}\text { Capital } \\
\text { humano }\end{array}$ & $\begin{array}{l}\text { Fase 1: El éxito del } \\
\text { estatus de la clase } \\
\text { media, basado en un } \\
\text { alto capital humano }\end{array}$ & $\begin{array}{l}\text { Profesionistas y } \\
\text { empresarios y una } \\
\text { completa aculturación }\end{array}$ & $\begin{array}{l}\text { Integración completa en la } \\
\text { vida social y económica }\end{array}$ \\
\hline $\begin{array}{l}\text { Composición } \\
\text { familiar }\end{array}$ & $\begin{array}{l}\text { Fase 2: Padres de } \\
\text { clase trabajadora } \\
\text { pero con fuerte } \\
\text { comunidad étnica }\end{array}$ & $\begin{array}{l}\text { Aculturación selectiva* } \\
\text { logro del estatus de la } \\
\text { clase media a través de } \\
\text { la educación }\end{array}$ & $\begin{array}{l}\text { Integración y aculturación } \\
\text { plena en la corriente } \\
\text { dominante }\end{array}$ \\
\hline $\begin{array}{l}\text { Modos de } \\
\text { incorporación }\end{array}$ & $\begin{array}{l}\text { Fase 3: Padres de } \\
\text { clase trabajadora y } \\
\text { débil comunidad } \\
\text { étnica }\end{array}$ & $\begin{array}{l}\text { Aculturación } \\
\text { disonante** y bajo } \\
\text { éxito educativo }\end{array}$ & $\begin{array}{l}\text { a. Estancamiento en } \\
\text { trabajos manuales } \\
\text { subordinados } \\
\text { b. Asimilación } \\
\text { descendente en un } \\
\text { estilo de vida desviado }\end{array}$ \\
\hline
\end{tabular}

*Se define como la preservación de la lengua y los elementos de la cultura paterna a través de la adquisición del inglés y del estilo de vida americano.

**Se define como el rechazo de la cultura de los padres y la ruptura de la comunicación a través de las generaciones.

Fuente: Portes, Fernandez-Kelly y Haller 2009: 1080.

La teoría de la asimilación segmentada consta de tres partes: 
a) una identificación de los principales factores exógenos que están en juego, b) una descripción de las principales barreras que enfrentan los hijos de inmigrantes de hoy en día, y c) una predicción de las trayectorias distintas que se espera de la interacción de estas fuerzas. Los factores exógenos pueden ser conceptualizados como los principales recursos (o falta de ellos) que las familias inmigrantes aportan a la confrontación con los desafíos externos que enfrentan los hijos. Estos factores son: 1) el capital humano que poseen los padres inmigrantes, 2) el contexto social que los recibe en Estados Unidos, y 3) la composición de las familias de inmigrantes (Portes, Fernandez-Kelly y Haller 2009: 1079).

En ese sentido, los miembros de la segunda generación del conjunto de familias que emigran y se instalan en distintos puntos de Estados Unidos no están exentos de mostrar una asimilación a la baja, panorama que debe ser explicado a partir de los elementos teóricos que ha proporcionado la teoría de la asimilación segmentada.

Más allá de los elementos que entran en juego en las dos perspectivas teóricas mencionadas, es necesario agregar que el contexto social y cultural del lugar de origen de las familias inmigrantes es un elemento que no contempla ninguna de las dos perspectivas y que es indispensable considerar en los estudios posteriores, dada su relevancia en el tema.

\section{CONSIDERACIONES FINALES}

La propuesta de marco teórico alterno nos ayudará a comprender de mejor manera la complejidad que suscita el desarrollo de las aspiraciones y el éxito educativo de los hijos de inmigrantes mexicanos, ya que el nuevo enfoque aquí propuesto considera una serie de ámbitos que el modelo alcanzar el estatus y el modelo las oportunidades bloqueadas no han contemplado, pero además va más allá de la teoría de la asimilación segmentada dado que aporta una serie de elementos que no han sido planteados para examinar más íntegramente el proceso de adaptación de los hijos de inmigrantes mexicanos en Estados Unidos. Aquí nos adentramos en explorar las relaciones paternofiliales que se generan 
dentro del hogar, dando importancia directa a las opiniones y acciones de los individuos involucrados porque en gran medida las decisiones son individuales, más que familiares. Sin embargo, existen cuatro ámbitos o perspectivas que no deben dejarse de lado, y que deben tomarse en consideración, ellos son: la perspectiva desde el hogar, factores de contexto, el ámbito escolar y la perspectiva personal o individual. Todas ellas forman parte del desarrollo de las aspiraciones educativas y del éxito académico de los hijos de inmigrantes mexicanos (véase Cuadro 4). Estos cuatro ámbitos o perspectivas están entrelazados pero a la vez tienen vida propia. En esta propuesta teórica se pone mayor énfasis en explorar la perspectiva del hogar, aunque sin dejar de lado los demás ámbitos señalados en el Cuadro 4.

Todos estos aspectos mencionados son fundamentales para hacer un análisis más completo, lo que permite visualizar el fenómeno desde una mirada binacional, es decir, desde el lugar de origen de los hijos y las familias inmigrantes, así como desde el lugar de destino, con el fin de proporcionarnos una serie de elementos que hasta ahora no han sido considerados en los estudios sobre la segunda generación de inmigrantes de origen mexicano. 
Norteamérica y sus aspiraciones educativas: una nueva propuesta teórica

\section{Cuadro 4. Esquema Aspiraciones Educativas. ${ }^{7}$}

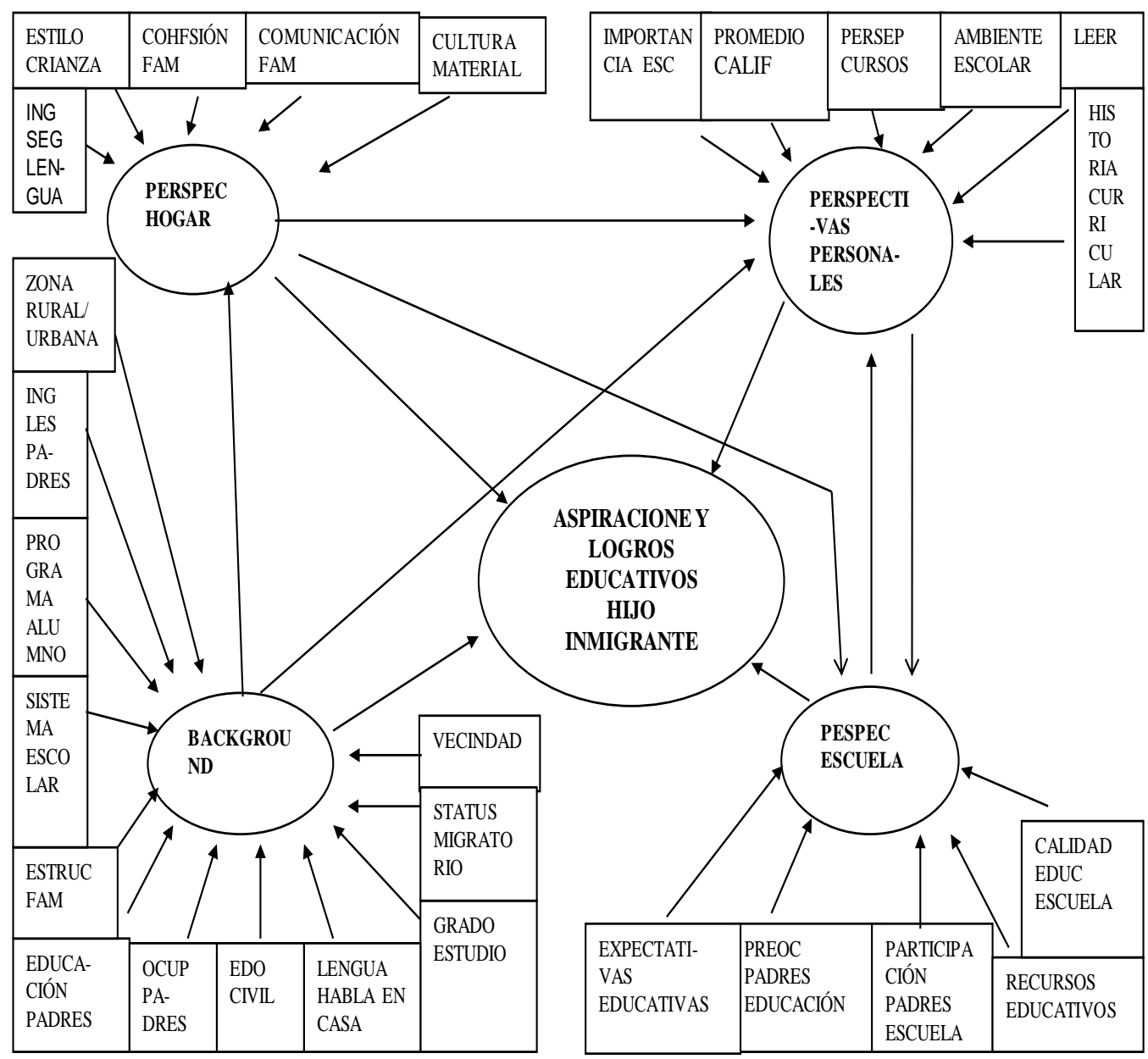


Leyenda del Cuadro 4. Factores que intervienen en el desarrollo de las aspiraciones y los logros educativos de los hijos de inmigrantes mexicanos en Estados Unidos.

\begin{tabular}{|l|l|}
\hline \multicolumn{2}{|c|}{ Perspectivas desde el Hogar } \\
\hline ESTILO CRIANZA & Estilo de Crianza de los Padres \\
\hline COHESIÓN FAM & Grado de Cohesión Familiar \\
\hline COMUNICACIÓN FAM & Grado de Comunicación de la familia sobre temas actuales de tipo social \\
\hline CULTURA MATERIAL & Cultura Material para la Educación \\
\hline ING SEG LENGUA & Inglés como Segunda Lengua \\
\hline
\end{tabular}

\begin{tabular}{|l|l|}
\hline \multicolumn{2}{|c|}{ Factores de Contexto } \\
\hline BACKGROUND (SES) & Estatus socioeconómico de los padres \\
\hline EDUCACIÓN PADRES & Nivel de educación de los padres \\
\hline OCUPPADRES & Nivel de ocupación de los padres \\
\hline EDO. CIVIL & Estado civil de los padres \\
\hline LENGUA HABLA EN CASA & Lengua que se habla en casa \\
\hline GRADO ESTUDIO & Grado o nivel de estudio del hijo \\
\hline ESTATUS MIGRATORIO & Estatus migratorio de los padres/hijo \\
\hline ZONA RURAL/URBANA & Zona rural/urbana donde vive la familia \\
\hline INGLÉS PADRES & Nivel de inglés de los padres \\
\hline PROGRAMA ALUMNO & Programa en el que está inscrito el alumno \\
\hline SISTEMA ESCOLAR & Conocimiento de los padres sobre el sistema escolar \\
\hline ESTRFAM & Estructura familiar \\
\hline VECINDARIO & Tipo de vecindario donde vive la familia inmigrante \\
\hline
\end{tabular}

\begin{tabular}{|l|l|}
\hline \multicolumn{2}{|c|}{ Perspectivas de la Escuela } \\
\hline EXPECTATIVAS EDUCACIÓN & Expectativas educativas de los padres hacia sus hijos \\
\hline PREOCUP PADRES EDUCACIÓN & Preocupación de los padres por la educación \\
\hline PARTICIPACIÓN PADRES ESCUELA & Participación de los padres en la escuela \\
\hline RECURSOS EDUCATIVOS & Recursos educativos fuera de la escuela \\
\hline CALIDAD EDUC ESCUELA & Calidad de la educación de la escuela \\
\hline
\end{tabular}

\begin{tabular}{|l|l|}
\hline \multicolumn{2}{|c|}{ Perspectivas Personales o individuales } \\
\hline IMPORTANCIA ESCUELA & Importancia de la escuela y de hacer tareas \\
\hline PROMEDIO CALIF & Promedio de calificaciones del alumno \\
\hline PERCEPCIÓN CURSOS & Percepción de los cursos como utilidad para su vida futura \\
\hline AMBIENTE ESCOLAR & Percepción del ambiente escolar \\
\hline LEER & Lo que leen los alumnos fuera de la escuela \\
\hline HISTORIAL CURRICULAR & Historial curricular del alumno \\
\hline
\end{tabular}




\section{FUENTES DE CONSULTA}

Alexander, Karl L., Bruce K. Eckland, and Larry J. Griffin, 1975, «The Wisconsin Model of Socioeconomic Achievement: A Replication», American Journal of Sociology, n. 81, pp. 324-342.

Arias, Patricia, 2009, Del arraigo a la diáspora. Dilemas de la familia rural, Miguel Ángel Porrúa, México.

Arias, Patricia (en prensa), «Migración, economía campesina y ciclo de desarrollo doméstico. Discusiones y estudios recientes», en Estudios Demográficos y Urbanos. El Colegio de México, v. 28, n. 82, primer cuatrimestre.

Ariza, Marina y Alejandro Portes, 2007, El país trasnacional migración mexicana y cambio social a través de la frontera, IIS UNAM, México.

Breen, R. y J. H. Goldthorpe, 1997, «Explaining educational differentials: towards a formal rational action theory», Rationality and Society, n. 9, pp. 275-305.

Cerrutti, Marcela y Magalí Gaudio, 2010, «Diferencia de género entre la migración a Estados Unidos y la de Paraguay a la Argentina», en Donato et al., (coords.), Salvando fronteras, Miguel Ángel Porrúa, México, pp. 95-118.

Cordasco, Francesco, 1973, «The children of immigrant in the schools: Historical analogues of educational deprivation», The Journal of Negro Education, v. 42, n. 1, pp. 4453.

Dreby, Joanna, 2010, Divided by Borders Mexican migrants and their children, University of California Press, Los Ángeles. 
Durand, Jorge, 1994, Más allá de la línea: Patrones migratorios entre México y Estados Unidos, Conaculta, México.

Durand, Jorge y Enrique Martínez Curiel, 1999, «Los nuevos procesos de integración. Matrimonios mixtos, y migración México-Estados Unidos: nuevas tendencias», en Fronteras Fragmentadas. Género, familia e identidades en la migración mexicana al norte, El Colegio de Michoacán, CIDEM, México, pp. 437-449.

Esteinou, Rosario y Daniel Nehring, 2009, «Educación familiar y estilos parentales en México: Una exploración de la Encuesta Nacional de la Dinámica Familiar», en Rosario Esteinou (ed.), Construyendo relaciones y fortalezas familiares, Ciesas, Miguel Ángel Porrúa, México, pp. 87-128.

Fuligni, Andrew J., 1997, «The academic achievement of adolescents from immigrant families: The roles of family background, attitudes, and behavior», Child Development, v. 68, n. 2, pp. 351-363.

Garcia Coll, Cynthia y Katherine Magnunson, 1997, «The Psychological Experience of Immigration: A Developmental Perspective», Immigration and the Family, Laurence Erlbaum Associates Inc., pp. 91-131.

Garrison, Howard H., 1982, «Trends in Educational and Occupational Aspirations of High School Males: Black-White Comparisons» Sociology of Education, n. 55, pp. 53-62.

Goyette, Kimberly y Yu Xie, 1999, «Educational expectations of Asian American youths: determinants and ethnic differences», Sociology of Education, n. 72, pp. 22-36.

Grebler, Leo, Joan Moore y Ralph Guzman, 1970, The Mexican American People: The Nation's Second Largest Minority, New York, Free Press. 
Guttormsson, Loftur, 2003, «Las relaciones paternofiliales», en David I. Kertzer y Marzio Barbagli (comps.), Historia de la familia europea, v. 2. Paidós, pp. 369-410.

Haller, Archibald D. y Alejandro Portes, 1973, «Status attainment processes», Sociology of Education, n. 46, pp. 51-91.

Hao, Lingxing y Melissa Bonstead-Bruns, 1998, «Parent-child differences in educational expectations and the academic achievement of immigrant and native students», Sociology of Education, n. 71, pp. 175-198.

Hao, Lingxing y Bonstead Bruns, M., 1998, «Parent-child differences in educational expectations and the academic achievement of immigrant and native students», Sociology of Education, n. 71, pp. 175-198.

Hauser, R.M. y Anderson, D. K., 1991, «Post high-school plans and aspirations of black and white high school seniors: 1976-1986», Sociology of Education, n. 64, pp. 263-277.

Kao, Grace y Marta Tienda, 1995, «Optimism and Achievement: The Educational Performance of Immigrant Youth», Social Science Quarterly, n. 76, pp. 1-21.

Kao, Grace y Marta Tienda, 1998, «Educational aspirations of minority youth», American Journal of Education, n. 106, pp. 349-384.

Khattab Nabil, 2003, «Explaining educational aspirations of minority students: the role of social capital and students' perceptions», Social Psychology of Education, n. 6, pp. 283302.

Levit, Peggy y Mary C. Waters, 2002, The changing face of home: the transnational lives 
Norteamérica y sus aspiraciones educativas: una nueva propuesta teórica

of the second generation, Russell Sage Foundation, New York.

MacLeod, Jay, 2008, Ain't No Makin' It: Aspirations and Attainment in a Low-Income Neighborhood, Westview Press, Portland.

Marjoribanks, Kevin, 1998, «Family background, social and academic capital, and adolescents' aspirations: A mediational analysis», Social Psychology of Education, n. 2, pp. 177-197.

Martínez Curiel, Enrique, 2003, Hasta que la green card nos separe, Universidad de Guadalajara, México.

Martínez Curiel, Enrique, 2004, «The Green Card as a Matrimonial Strategy: Self-Interest in the Choice of Marital Partners», en Jorge Durand y Douglas S. Massey (eds.), Crossing the Border, Russell Sage Fundation, New York, pp. 86-108.

Massey Douglas, Rafael Alarcón, Jorge Durand y Humberto González, 1991, Los Ausentes. El proceso social de la migración internacional en el occidente de México, Alianza editorial, México.

Mickelson, R. A., 1990, «The attitude-achievement paradox among black adolescents», Sociology of Education, n. 63, pp. 44-61.

Morgan, S. L., 1996, «Trends in black-white differences in educational expectations, 19801992», Sociology of Education, n. 69, pp. 308-319.

Ogbu, John U., 1983, «Minority Status and Schooling in Plural Societies», Comparative Education Review, v. 27, n. 2, pp. 168-190. 
Norteamérica y sus aspiraciones educativas: una nueva propuesta teórica

Ogbu, John U., 1992, «Understanding Cultural Diversity and Learning», Educational Researcher, v. 21, n. 8, pp. 5-14.

Ogbu, John. U. y Simons, H. D., 1998, «Voluntary and involuntary minorities: A CulturalEcological Theory of school performance with some implications for education», Anthropology and Education Quarterly, n. 29, pp. 155-188.

Portes Alejandro y Jay MacLeod, 1996, «Educational Progress of Children of Immigrants: The Roles of Class, Ethnicity, and School Context», Sociology of Education, v. 69, n. 4, pp. $255-275$.

Portes Alejandro y Min Zhou, 1992, «Gaining the upper hand: economic mobility among immigrant and domestic minorities», Ethnic and Rural Studies, v. 15, pp. 491-522.

Portes, Alejandro y Min Zhou, 1993, «The New Second Generation: Segmented Assimilation and Its Variants», Annals of the American Academy of Political and Social Science, n. 530, pp. 74-96.

Portes, Alejandro y Rubén G. Rumbaut, 1996, Immigrant America: A Portrait, University of California Press, Los Angeles.

Portes, Alejandro y Rubén G. Rumbaut, 2001, Ethnicities, University of California Press, Los Angeles.

Portes, Alejandro, Patricia Fernández-Kelly y William Haller, 2009, «The Adaptation of the Immigrant Second Generation in America: A Theoretical Overview and Recent Evidence», Journal of Ethnic and Migration Studies, v. 35, n. 7, agosto, pp. 1077-1104.

Portes, Alejandro, 2006, «La nueva nación latina: inmigración y la población hispana de los 
Norteamérica y sus aspiraciones educativas: una nueva propuesta teórica

Estados Unidos», Reis, n. 116, pp. 55-96.

Rumbaut, Rubén G., 1997, «Ties that bind: Immigration and immigrant families in the United States» Immigration and the Family, Laurence Erlbaum Associates Inc., pp. 3-46.

Russell Rumberger, 1983, «Dropping out of High School: The influence of race, sex and family background», American Educational Research Journal, v. 20, n. 2, pp. 199-220.

Scheneider, B. y D. Stevenson, 1999, The ambitious generation: America's teenagers, motivated but directionless, Yale University Press, New Haven and London.

Schmid, Carol L., 2001, «Educational achievement, Language-Minority students and the new second generation», Sociology of Education, v. 74, pp. 71-87.

Sewell, William. H., 1971, «Inequality of Opportunity for Higher Education», American Sociological Review, n. 36, pp. 793-809.

Sewell, William H. y Vimal P. Shah, 1968, «Parents’ Education and Children's Educational Aspirations and Achievements», American Sociological Review, n. 33, pp. 191-209.

Sewell, William H., Archibald O. Haller, and George W. Ohlendorf, 1970, «The Educational and Early Occupational Status Attainment Process: Replication and Revision», American Sociological Review, n. 35, pp. 1014-1027.

Sewell, William H. y Robert M. Hauser, 1980, «The Wisconsin Longitudinal Study of Social and Psychological Factors in Aspirations and Achievements», Research in Sociology of Education and Socialization, n. 1, pp. 59-99.

Sewell, William H. y Robert M. Hauser, 1993, A Review of the Wisconsin Longitudinal 
Study of Social and Psychological Factors in Aspirations and Achievements 1963-1992, Department of Sociology, The University of Wisconsin, Madison.

Solórzano, D. G., 1992, «An exploratory analysis of the effects of race, class, and gender on student and parent mobility aspirations», Journal of Negro Education, n. 61, pp. 30-43.

Smith, Robert Courtney, 2006, México en Nueva York, UAZ, Miguel Ángel Porrúa, México.

Smith, Timothy. L., 1969, «Immigrant social aspirations and American education, 18801930», American Quarterly, v. 21, n. 3, pp. 523-543.

Telles, Edward E. y Vilma Ortiz, 2008, Generations of Exclusion Mexican Americans Assimilation and Race, Russell Sage Fundation, New York.

Warren, John Robert, 1996, «Educational inequality among White and Mexican-origin adolescents in the American southwest:1990», Sociology of Education, n. 69, pp. 142-158.

Wolf, D. L., 1990, «Daughters, Decisions and Domination: An Empirical and Conceptual Critique of Household Strategies», Development and Change, v. 21, pp. 43-74.

Zhou, Min, 1997, «Segmented Assimilation: Issues, Controversies, and Recent Research on the New Second Generation», International Migration Review, v. 31, n. 4, pp. 975-1008.

\section{NOTAS}

\footnotetext{
${ }^{1}$ Algunos de los trabajos que lo señalan son: The changing face of home: the transnational lives of the second generation, de Levitt, P. y M. C. Waters, New York, Russell Sage Foundation. 2002. Y el trabajo de MacLeod, Jay. Ain't No Makin' It: Aspirations and Attainment in a Low-Income Neighborhood. Westview Press. 2008.

${ }^{2}$ Cuando se habla de la segunda generación me estoy refiriendo a los hijos nacidos en Estados Unidos de padres inmigrantes, y cuando se habla de los hijos nacidos en el extranjero que emigraron a Estados Unidos al
} 
inicio de la edad escolar y hasta antes de la adolescencia (6-12 años) se denomina como la generación 1.5 (Rumbaut 1997, Portes y Rumbaut 2001).

${ }^{3}$ La Ley de Inmigración y Naturalización de 1965 revoca el sistema de cuotas por origen nacional bajo la ley anterior de 1952, donde se permitía que $2 \%$ de la población total de una nación extranjera emigrara legalmente cada año a Estados Unidos. En vez de considerar la nacionalidad y el origen étnico, la enmienda de 1965 estableció un sistema basado en la reunificación de las familias y en las destrezas de los trabajadores inmigrantes. La ley de 1965 otorgó visas individuales, dándose prioridad a la reunificación de la familia y a quienes tuvieran habilidades requeridas en Estados Unidos.

${ }^{4}$ Aunque también esta categorización debe incluir a los mexicanos que emigran en busca de trabajo.

${ }^{5}$ El contexto de recepción y los modos de incorporación en la sociedad norteamericana son dos elementos importantes que forman parte de la teoría de la asimilación segmentada, planteada por Portes y Zhou.

${ }^{6} \mathrm{Al}$ hablar de los fuertes lazos o vínculos entre la familia nos estamos refiriendo a las relaciones paterno filiales que establecen los padres e hijos dentro de una unidad doméstica definida.

${ }^{7}$ Para la construcción del esquema se tomó como base el trabajo de Rashmi Garg, Carol Kauppi, John Lewko y Diana Urajnik. «A Structural Model of Educational Aspirations», Journal of Career Development, vol. 29, núm. 2, invierno 2002.

Fecha de recepción: 9 de marzo de 2012.

Fecha de aceptación: 8 de septiembre de 2012. 